\title{
DAKTILITAS KURVATUR PENAMPANG KOLOM BETON BERTULANG TERKEKANG CINCIN BAJA
}

\author{
Endah Safitri \\ Prodi Teknik Sipil, Universitas Sebelas Maret, Jl. Ir. Sutami 36 A Surakarta \\ Email: safitri47@gmail.com
}

\begin{abstract}
ABSTRAK
Struktur perlu didesain mempunyai daktilitas yang tinggi agar mendapatkan struktur yang relatif kuat menahan beban gempa (earthquake resistant building). Pada elemen beton bertulang, pengekangan efektif pada elemen struktur yang menerima gaya aksial tekan dominan yaitu kolom. Kekangan yang umum dipakai selama ini pada kolom adalah internal confinement. Paper ini membahas tentang external confinement sebagai alternatif lain dari pengekangan kolom. Sebagai external confinement dipakai tabung silinder baja yang dipotong dengan lebar tertentu sehingga mirip cincin baja. Efek kekangan yang berbeda pada beton didapat dari variasi nilai rasio volumetrik cincin baja. Daktilitas kurvatur meningkat seiring dengan semakin besarnya rasio volumetrik cincin baja. Hal ini dikarenakan semakin besar rasio volumetrik cincin baja, maka daerah kekangan semakin luas sehingga beton mampu berdeformasi lebih besar. Meningkatnya kemampuan beton dalam berdeformasi ini akan meningkatkan daktilitas beton. Kenaikan optimum daktilitas kurvatur penampang kolom beton bertulang terkekang cincin baja tercapai pada rasio volumetrik $1,85 \%$.
\end{abstract}

Kata kunci: daktilitas kurvatur, kekangan, kolom beton bertulang

\section{PENDAHULUAN}

Daktilitas diperlukan pada elemen beton bertulang untuk menciptakan struktur yang relatif kuat menahan beban gempa tetapi ekonomis (earthquake resistant building) (Pawirodikromo, 2012). Struktur perlu didesain mempunyai daktilitas yang tinggi terutama pada elemen kolom paling bawah, agar struktur mampu berdeformasi dengan simpangan lateral yang besar. Salah satu cara untuk meningkatkan daktilitas pada kolom struktur paling bawah adalah dengan pengekangan elemen beton bertulang. Kolom yang dikekang memiliki kekuatan lebih besar daripada kolom yang tidak dikekang. Hal ini karena akibat kekangan akan menambah besar tegangan dan regangan tekan maksimum (Mander et.al., 1988).

Pada elemen beton bertulang, pengekangan efektif pada daerah tekan penampang beton terutama pada elemen struktur yang menerima gaya aksial tekan dominan yaitu kolom. Kekangan yang umum dipakai selama ini pada kolom adalah internal confinement berupa tulangan sengkang baik spiral maupun persegi. Berbagai penelitian tentang internal confinement telah banyak dilakukan. Berbagai variasi konfigurasi tulangan sengkang diteliti untuk menghasilkan daerah kekangan yang lebih baik pada beton. Tulangan lateral tersebut berfungsi sebagai tulangan geser sekaligus sebagai pengekang (confined) beton agar tidak terjadi pengurangan inti (core) beton yang berlebihan (akibat pecahnya beton) terutama pada kolom yang mendapat beban aksial tinggi. Akibat hilangnya selimut beton pada SNI 03-2847-2002 pasal 23.4.4. memuat persamaan rumus yang mangakomodir bila terjadi spalling pada pelindung beton tidak akan menyebabkan kehilangan kekuatan beban aksial kolom (Purwono dkk, 2007). Akan tetapi spalling sangat merugikan pada elemen struktur yang bersangkutan karena tulangan longitudinal kolom yang kelihatan beresiko korosi yang akan menyebabkan penurunan kekuatan tulangan tersebut.

Oleh karena itu, paper ini bertujuan untuk mengkaji pengaruh kekangan external confinement sebagai alternatif lain dari pengekangan yang diharapkan selain mampu meningkatkan daktilitas beton juga mampu menyelamatkan selimut beton.

\section{KAJIAN PUSTAKA}

Daktilitas menunjukkan kemampuan struktur dalam menahan pengaruh deformasi akibat kondisi pembebanan yang berlebihan (Park and Ruitong, 1988). Daktilitas pada umumnya ada dua macam, yaitu daktilitas lengkung (curvature ductility) dan daktilitas simpangan (displacement ductility) (Paulay and Priestlay, 1992). 

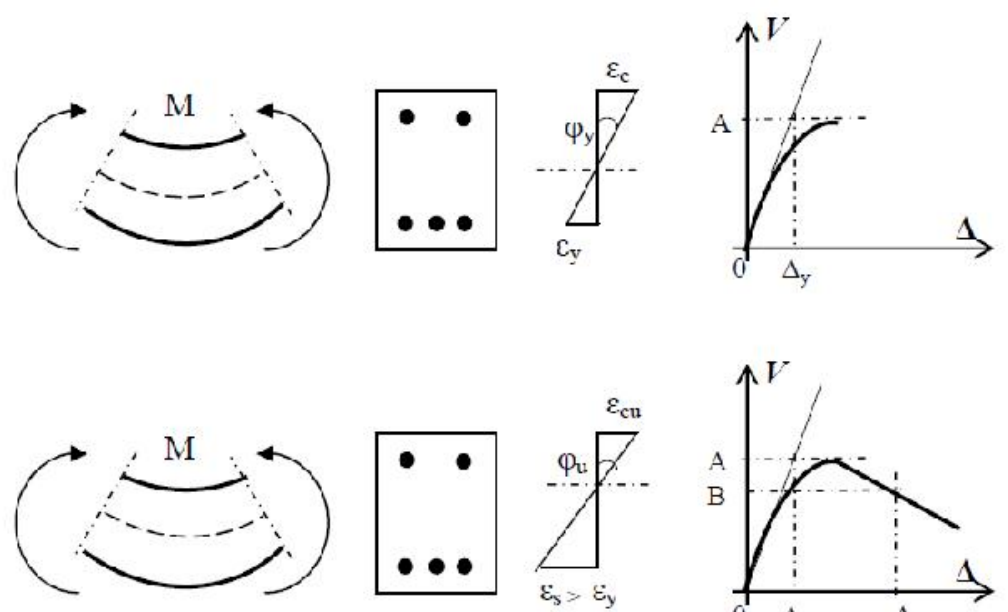

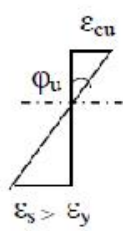

a).

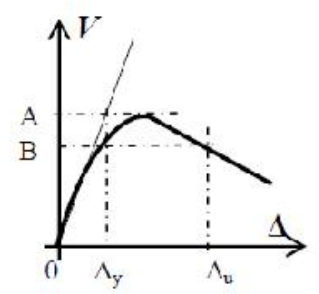

b).

Gambar 1. Daktilitas : a) Kurvatur dan b) Perpindahan (Pawirodikromo, 2012)

Pada Gambar 1 terlihat daktilitas kurvatur adalah perbandingan antara sudut rotasi per-unit panjang (kelengkungan) $\varphi_{\mathrm{u}}$ pada kondisi ultimit dan $\varphi_{\mathrm{y}}$ pada kondisi leleh pertama, atau

$$
\mu_{\varphi}=\frac{\varphi_{u}}{\varphi_{y}}
$$

Sementara itu daktilitas simpangan adalah rasio antara simpangan ultimit u dengan simpangan saat leleh pertama y, atau

$$
\mu_{\Delta}=\frac{\Delta_{u}}{\Delta_{y}}
$$

Pada pembebanan siklik bolak balik, hubungan antara beban dan simpangan ditunjukkan oleh garis lengkung/nonlinier putus-putus yang membentuk suatu siklus tertutup yang umumnya disebut hysteretic loops. Untuk menentukan simpangan leleh pada garis lengkung tersebut agak kesulitan. Oleh karena itu di dalam dinamik analisis, perilaku non-linier diatas dapat dimodel sebagai model histeresis elstoplastis. Dengan model elastoplastis maka simpangan saat leleh y dan simpangan ultimit u dapat ditentukan relatif mudah (Gambar 2).

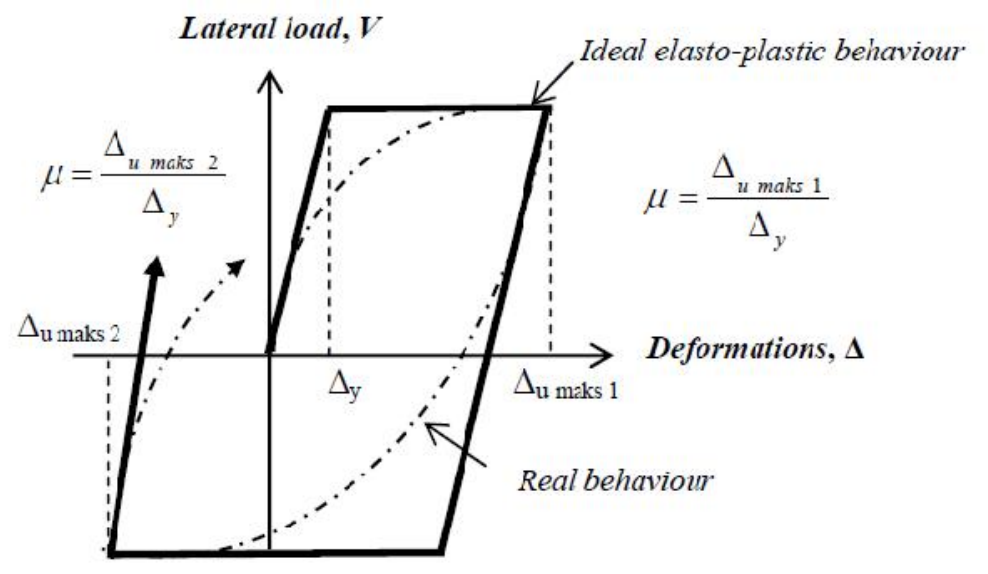

Gambar 2. Daktilitas Perpindahan (Park, 1989)

Untuk menyelamatkan selimut beton, akhir-akhir ini dikembangkan penelitian tentang external confinement. Salah satu contohnya adalah Concrete Filled Steel Tubes (CFST). CFST adalah elemen struktur komposit yang terdiri dari sebuah tabung baja dan beton pengisi. Tabung baja disini berperan sebagai external confinement sekaligus external reinforcement. CFST mengoptimalkan kontribusi kedua komponen dengan meningkatkan efisiensi geometrik dan sepenuhnya menggunakan kekuatan yang ada pada mereka. Beton pengisi dikekang oleh tabung baja, sehingga dalam kondisi tekanan triaksial akan meningkatkan kapasitas kekuatan dan regangan beton (Roeder et.al., 2010). 
Pada penelitian ini cincin baja hanya berfungsi sebagai external confinement, sehingga tidak perlu menyelubungi seluruh tinggi kolom dan dapat menghemat biaya konstruksi.

\section{METODE PENELITIAN}

Untuk mengetahui efek kekangan external confinement terhadap daktilitas kurvatur penampang kolom beton bertulang dipakai hasil penelitian pendahuluan silinder beton dengan cincin baja sebagai external confinement-nya. Tabung silinder baja ini dipotong dengan lebar tertentu $(a)$ sehingga mirip cincin. Cincin baja tersebut dipasang dengan jarak tertentu antar cincin $(b)$ seperti terlihat pada Gambar 3. Dengan variasi nilai a/b akan didapatkan variasi nilai rasio volumetrik cincin baja seperti yang disajikan dalam Tabel 1.

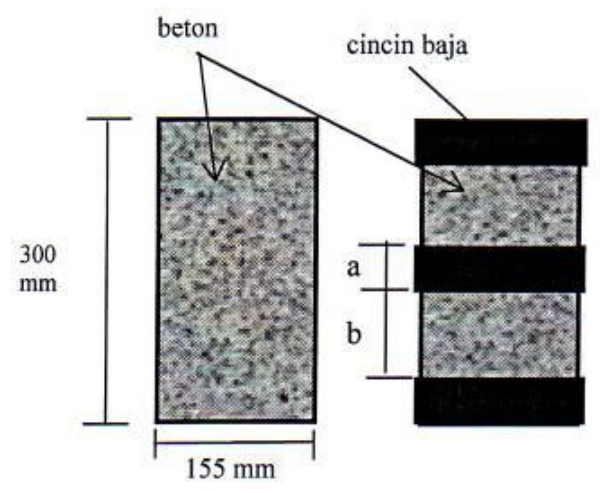

Gambar 3. Benda uji silinder beton terkekang cincin baja

Tabel 1. Varian benda uji

\begin{tabular}{llc}
\hline \multicolumn{1}{c}{ Benda Uji } & \multicolumn{1}{c}{ Kode } & Rasio volumetrik $(\rho)$ \\
\hline Beton tak terkekang & BTT & 0 \\
\hline \multirow{2}{*}{ Beton terkekang variasi jarak antar cincin baja } & BT 40/130 & 1,25 \\
& BT 40/87 & 1,66 \\
& BT 40/65 & 2,08 \\
Beton terkekang variasi lebar cincin baja & BT 28/68 & 1,46 \\
& BT 45/85 & 1,87 \\
\hline
\end{tabular}

Ditinjau suatu penampang kolom beton bertulang berbentuk lingkaran diameter $260 \mathrm{~mm}$ dengan tulangan longitudinal 8D13, tulangan transversal $\varnothing 8$, Mutu beton $f_{c}{ }^{\prime}=25 \mathrm{MPa}$ dan mutu tulangan baja $f_{y}=400 \mathrm{MPa}$, selimut beton $25 \mathrm{~mm}$ seperti yang diperlihatkan di Gambar 4.

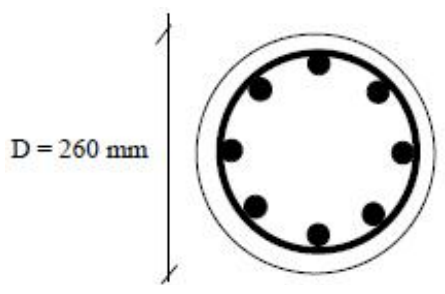

Gambar 4. Penampang kolom tertinjau

\section{HASIL DAN PEMBAHASAN}

Berdasarkan analisa perhitungan dengan menggunakan variasi pembebanan $P_{n}=0 ; 0,25 P_{n b} ; 0,5 P_{n b} ;$ dan $0,75 P_{n b}$, maka didapatkan daktilitas kurvatur penampang kolom beton bertulang yang disajikan dalam Tabel $2 \mathrm{a}$ dan Tabel $2 \mathrm{~b}$.

Tabel 2a. Daktilitas Kurvatur Penampang Kolom Beton Bertulang Terkekang Cincin Baja untuk Berbagai Rasio Volumetrik (Variasi Jarak Antar Cincin Baja) pada Berbagai Pembebanan 


\begin{tabular}{|c|c|c|c|c|c|c|}
\hline \multicolumn{7}{|c|}{ Variasi Jarak Antar Cincin Baja } \\
\hline \multirow{3}{*}{ Pembebanan } & Benda Uj1 & \multicolumn{2}{|c|}{$\begin{array}{c}\text { Beton tak } \\
\text { terkelkang (BTT) }\end{array}$} & \multicolumn{3}{|c|}{ Beton terkekang (BT) } \\
\hline & Kode & & & BT $40 / 130$ & BT 40/87 & BT 40/65 \\
\hline & Rasio volumetrik $\rho(\%)$ & & & 1,25 & 1,66 & 2,08 \\
\hline \multirow{4}{*}{$P_{n}=0$} & $\varphi_{y}\left(10^{-6} \mathrm{rad} / \mathrm{mm}\right)$ & & 14,815 & 14,707 & 15,297 & 15,643 \\
\hline & $\varphi_{\text {ult }}\left(10^{-0} \mathrm{rad} / \mathrm{mm}\right)$ & & 55.586 & 191.320 & 246.673 & 236.964 \\
\hline & Daktilitas kurvatur $\left(\mu_{\varphi}\right)$ & 3.752 & & 13.009 & 16.126 & 15,148 \\
\hline & Peningkatan daktilitas (\%) & & - & 246,72 & 329,80 & 303,73 \\
\hline \multirow{4}{*}{$P_{n}-0,25 P_{n b}$} & $\varphi_{y}\left(10^{-6} \mathrm{radimm}\right)$ & & 17,982 & 24,156 & 23,512 & 23,556 \\
\hline & $\varphi_{\text {ult }}\left(10^{-6} \mathrm{rad} / \mathrm{mm}\right)$ & & 42,773 & 130,140 & 149,688 & 140,005 \\
\hline & Daktılitas kurvatur $\left(\mu_{0}\right)$ & 2,379 & & 5,387 & 6,366 & 5,943 \\
\hline & Peringkiatan dak tililias (\%) & & - & 120,44 & $16 \%, 59$ & 149,81 \\
\hline \multirow{4}{*}{$P_{n}=0,5 P_{n}$} & $\varphi_{y}\left(10^{-6}{ }_{1 a d}\right.$ & & 20,822 & 27,743 & 29,453 & 29,601 \\
\hline & $\varphi_{u l t}\left(10^{-6} \mathrm{rad} / \mathrm{mm}\right)$ & & 35,599 & 89,582 & 99,705 & 93,117 \\
\hline & Daltilitas kurvatur $\left(\mu_{\varphi}\right)$ & 1,710 & & 3,229 & 3,385 & 3,146 \\
\hline & Pcningkatan daktilitas (\%) & & - & 88,83 & 97,95 & 83,98 \\
\hline \multirow{4}{*}{$P_{n}=0,75 P_{n b}$} & $\varphi_{y}\left(10^{-6} \mathrm{rad} / \mathrm{mm}\right)$ & & 23,133 & 38.643 & 42,560 & 40,025 \\
\hline & $\varphi_{\text {ult }}\left(10^{-6} \mathrm{rad} / \mathrm{mm}\right)$ & & 29,928 & 71,611 & 78,948 & 73,331 \\
\hline & Dak.tihitas ku valun $\left(\mu_{\varphi}\right)$ & & 1,294 & 1,853 & 1,855 & 1,832 \\
\hline & Peningkatan daktilitas (\%) & & - & 43,20 & 43,35 & 41,58 \\
\hline \multirow{4}{*}{$P_{n}=P_{n b}$} & $\varphi_{y}\left(10^{-6} \mathrm{rad} / \mathrm{mm}\right)$ & & 26.304 & 58.730 & 63.946 & 59.637 \\
\hline & $\varphi_{u l t}\left(10^{-6} \mathrm{rad} / \mathrm{mm}\right)$ & & 26,304 & 58,730 & 63,946 & 59,637 \\
\hline & Daktilitas kurvatur $\left(\mu_{\varphi}\right)$ & & 1,000 & 1,000 & 1,000 & 1,000 \\
\hline & Peningkatan daktilitas (\%) & & - & 0 & 0 & 0 \\
\hline
\end{tabular}

Tabel 2b. Daktilitas Kurvatur Penampang Kolom Beton Bertulang Terkekang Cincin Baja untuk Berbagai Rasio Volumetrik (Variasi Lebar Cincin Baja) pada Berbagai Pembebanan

\begin{tabular}{|c|c|c|c|c|c|c|}
\hline \multicolumn{7}{|c|}{ Variasi Lebar Cincin Baja } \\
\hline \multirow{3}{*}{ Pembebanan } & Benda IJji & \multirow{2}{*}{\multicolumn{2}{|c|}{$\begin{array}{c}\text { Beton tak } \\
\text { terkekaug (BTT) } \\
\text { BTT }\end{array}$}} & \multicolumn{3}{|c|}{ Beton terkekang ( $\left.B^{\prime} I\right)$} \\
\hline & Kode & & & BT $28 / 68$ & BT $45 / 85$ & BT $73 / 113$ \\
\hline & Rasio volumetrik $p(\%)$ & & 0 & 1,46 & 1,87 & 2,28 \\
\hline \multirow{4}{*}{$P_{n}-0,25 P_{n b}$} & $\varphi_{3} \quad\left(10^{-6} \mathrm{rad} / \mathrm{mm}\right)$ & & 17,982 & 22,059 & 22,759 & 21,827 \\
\hline & $\varphi_{s t}\left(10^{-6} \mathrm{rad} / \mathrm{mm}\right)$ & & 42,773 & 169,038 & 163,436 & 163.704 \\
\hline & Daklilitas kurvalur $\left(\mu_{\varphi}\right)$ & 2,379 & & 7,663 & 7,181 & 7,500 \\
\hline & l'eningkatan daktilitas (\%) & & - & 222.11 & 201.85 & 215,26 \\
\hline \multirow{4}{*}{$P_{n}=0,5 P_{n s}$} & $\varphi_{3} \quad\left(10^{-6} \mathrm{rud} / \mathrm{mm}\right)$ & & 20,822 & 33,561 & 31,613 & 33.380 \\
\hline & $\varphi_{\text {: } h}\left(10^{6} \mathrm{rad} / \mathrm{mm}\right)$ & & 35,599 & 112,976 & 108,847 & 108,624 \\
\hline & Daktilitas kurvatur $\left(\mu_{\varphi}\right)$ & 1.710 & & 3.366 & 3.413 & 3,251 \\
\hline & Peningkatan daktilitas $(\%)$ & & - & 96.84 & 101.35 & 20.29 \\
\hline \multirow{4}{*}{$P_{n} \quad 0,75 P_{n b}$} & $\varphi_{y} \quad\left(10^{-6} \mathrm{rad} / \mathrm{mm}\right)$ & & 23,133 & 45,373 & 43,807 & 48,259 \\
\hline & $\varphi_{\mathrm{wh}}\left(10^{-6} \mathrm{rad} / \mathrm{mm}\right)$ & & 29,928 & 89,370 & 86.192 & 85,851 \\
\hline & Daktilitas kurvatur $\left(\mu_{\varphi}\right)$ & & 1,294 & 1,970 & 1,968 & 1,779 \\
\hline & Peningkatan daktilitas (\%) & & - & 52.24 & 52.09 & 37,48 \\
\hline \multirow{4}{*}{$P_{n} \quad P_{n \hat{b}}$} & Q. $\left(10^{-6} \mathrm{rad} / \mathrm{mm}\right)$ & & 26.304 & 72,336 & 69,615 & 69,388 \\
\hline & $\varphi_{u t}\left(10^{-6} \mathrm{rad} / \mathrm{mm}\right)$ & & 26,304 & 72,336 & 69,615 & 69,388 \\
\hline & Daktilitas kurvatur $\left(\mu_{\varphi}\right)$ & & 1,000 & 1.000 & 1,000 & 1.000 \\
\hline & Peningkatan daktilitas $(\%)$ & & - & 0 & 0 & 0 \\
\hline
\end{tabular}

Perhitungan optimasi dilakukan untuk mengetahui pada rasio volumetrik berapa daktilitas tercapai maksimum. Data-data daktilitas pada Tabel 2a dan 2b diplotkan pada diagram rasio volumetrik-daktilitas (Gambar 5). Persamaan grafik yang didapatkan pada berbagai pembebanan digunakan untuk mencari nilai titik optimasi, dengan mencari nilai $\frac{d y}{d x}=0$. Hasil perhitungan titik optimasi dapat dilihat pada Tabel $3 \mathrm{a}$ dan $3 \mathrm{~b}$. 


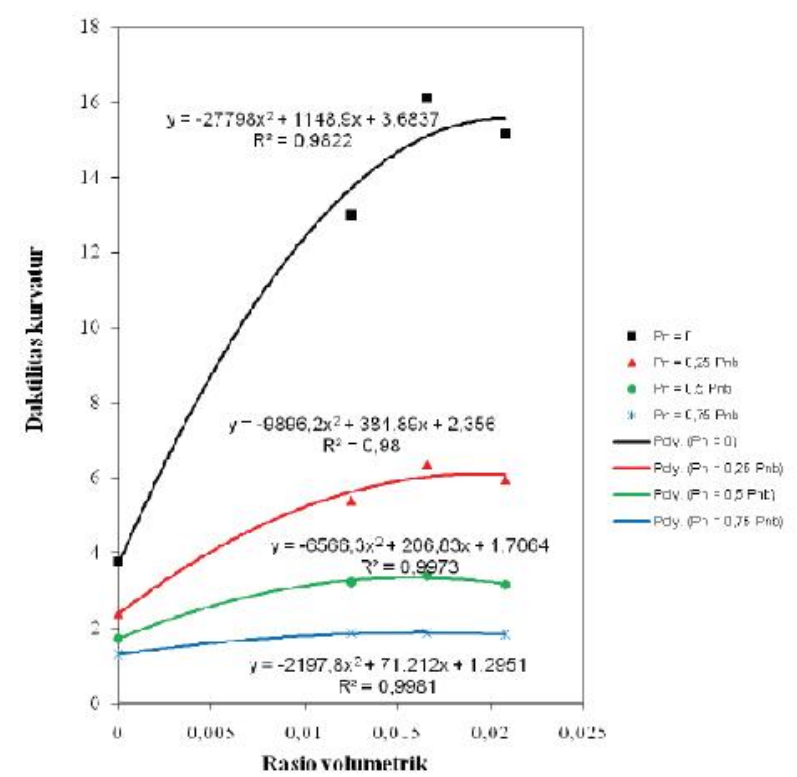

a. Variasi Jarak Antar Cincin Baja

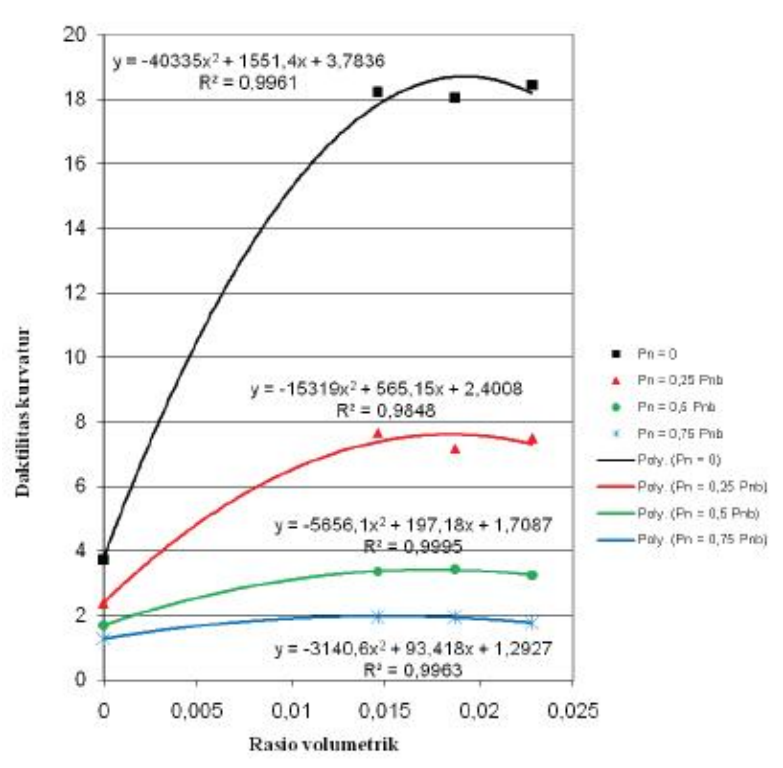

b. Variasi Lebar Cincin Baja

Gambar 5. Grafik Hubungan Antara Rasio Volumetrik dan Daktilitas Kurvatur Penampang Kolom Beton Bertulang Terkekang Cincin Baja untuk Berbagai Pembebanan

Tabel 3a. Persamaan Grafik Daktilitas Kurvatur Penampang Kolom Beton Bertulang Terkekang Cincin Baja untuk Berbagai Pembebanan (Variasi Jarak Antar Cincin Baja)

\begin{tabular}{|c|c|c|c|c|c|c|}
\hline \multirow{2}{*}{$\begin{array}{c}\text { Kondisi } \\
\text { Pembebanan }\end{array}$} & BTT & $\begin{array}{c}\text { BT } \\
40 / 130 \\
\end{array}$ & $\begin{array}{c}\text { BT } \\
40 / 87 \\
\end{array}$ & $\begin{array}{c}\text { BT } \\
40 / 65\end{array}$ & \multirow{2}{*}{$\begin{array}{l}\text { Optimasi pd } \\
\text { titik x (rasio } \\
\text { volumetrik) }\end{array}$} & \multirow{2}{*}{$\begin{array}{c}\text { Daktilitas } \\
\text { Kurvatur } \\
\text { pd ttk } \\
\text { optimasi }\end{array}$} \\
\hline & 0 & 0,0125 & 0,0166 & 0,0208 & & \\
\hline$P_{n}=0$ & 3,752 & 13,009 & 16,126 & 15,148 & 0,0215 & 15,5531 \\
\hline$P_{n}=0,25 P_{n b}$ & 2,379 & 5,387 & 6,366 & 5,943 & 0,0202 & 6,0988 \\
\hline$P_{n}=0,5 P_{n b}$ & 1,710 & 3,229 & 3,385 & 3,146 & 0,0164 & 3,3359 \\
\hline \multirow[t]{3}{*}{$P_{n}=0,75 P_{n b}$} & 1,294 & 1,853 & 1,855 & 1,832 & 0,0169 & 1,8722 \\
\hline & & & & jumlah & 0,0750 & \\
\hline & & & & rata-rata & 0,0188 & \\
\hline
\end{tabular}

Tabel 3b. Persamaan Grafik Daktilitas Kurvatur Penampang Kolom Beton Bertulang Terkekang Cincin Baja Untuk Berbagai Pembebanan (Variasi Lebar Cincin Baja)

\begin{tabular}{|c|c|c|c|c|c|c|}
\hline \multirow{2}{*}{$\begin{array}{c}\text { Kondisi } \\
\text { Pembebanan }\end{array}$} & BTT & $\begin{array}{c}\text { BT } \\
28 / 68\end{array}$ & $\begin{array}{c}\text { BT } \\
\mathbf{4 5 / 8 5} \\
\end{array}$ & $\begin{array}{c}\text { BT } \\
73 / 113 \\
\end{array}$ & \multirow{2}{*}{$\begin{array}{l}\text { Optimasi pd } \\
\text { titik x (rasio } \\
\text { volumetrik) }\end{array}$} & \multirow{2}{*}{$\begin{array}{c}\text { Daktilitas } \\
\text { Kurvatur } \\
\text { pd ttk } \\
\text { optimasi }\end{array}$} \\
\hline & 0 & 0,0146 & 0,0187 & 0,0228 & & \\
\hline$P_{n}=0$ & 3,752 & 18,237 & 18,063 & 18,444 & 0,0200 & 18,6977 \\
\hline$P_{n}=0,25 P_{n b}$ & 2,379 & 7,663 & 7,181 & 7,5 & 0,0192 & 7,6130 \\
\hline$P_{n}=0,5 P_{n b}$ & 1,71 & 3,366 & 3,443 & 3,254 & 0,0181 & 3,4270 \\
\hline \multirow[t]{3}{*}{$P_{n}=0,75 P_{n b}$} & 1,294 & 1,97 & 1,968 & 1,779 & 0,0155 & 1,9877 \\
\hline & & & & jumlah & 0,0727 & \\
\hline & & & & rata-rata & 0,0182 & \\
\hline
\end{tabular}

Rasio volumetrik rata-rata untuk kolom terkekang cincin baja variasi jarak antar cincin baja adalah $1,88 \%$, sedangkan untuk variasi lebar cincin baja adalah 1,82\%. Oleh karena itu rasio volumetrik rata-rata yang menghasilkan efek kekangan paling optimal adalah :

rasio volumetrik rata - rata $=\frac{0,0188+0,0182}{2}=0,0185$ 
Jadi daktilitas kurvatur optimum pada penelitian penampang kolom terkekang cincin baja ini terjadi pada rasio volumetrik cincin baja sebesar $1,85 \%$. Hal ini membuktikan bahwa kekangan eksternal cincin baja memberikan efek kekangan yang optimal pada rasio volumetrik yang besar.

\section{KESIMPULAN}

Berdasarkan uraian diatas maka dapat ditarik beberapa kesimpulan sebagai berikut :

1. Daktilitas kurvatur penampang kolom beton bertulang terkekang cincin baja untuk variasi jarak antar cincin baja meningkat seiring dengan peningkatan rasio volumetrik cincin baja.

2. Daktilitas kurvatur penampang kolom beton bertulang terkekang cincin baja untuk variasi lebar cincin baja meningkat seiring dengan peningkatan rasio volumetrik cincin baja.

3. Daktilitas kurvatur optimum pada penelitian penampang kolom terkekang cincin baja ini terjadi pada rasio volumetrik cincin baja sebesar $1,85 \%$.

\section{UCAPAN TERIMA KASIH}

Ucapan terima kasih kepada Kementrian Pendidikan dan Kebudayaan untuk pendanaan yang diberikan pada penelitian ini melalui Program Hibah Doktor, Penelitian dan Pengadian kepada Masyarakat Dana PNBP Universitas Sebelas Maret Tahun Anggaran 2015. Selain itu terima kasih juga untuk Laboratorium Bahan Teknik Sipil UNS dan Laboratorium Struktur Teknik Sipil UGM atas bantuan tempat pelaksanaan serta alat pengujiannya.

\section{DAFTAR PUSTAKA}

Badan Standardisasi Nasional, (2002), "SNI 03-2847-2002 Tata Cara Perhitungan Struktur Beton untuk Bangunan Gedung", Jakarta, Indonesia.

Mander, J.B., Pristley, M.J.N., and Park, R. (1988), "Theoretical Stress-Strain Model for Confined Concrete”, ASCE Journal of Structural Engineering, Vol. 114, No.8, Aug. 1988, pp. 1804-1826.

Mander, J.B., Priestley, M.J.N., and Park, R. (1988), "Observed Stress-Strain Behavior of Confined Concrete”, Journal of the Structural Division, ASCE, Vol. 114, No. 8, Aug. 1988, pp. 1827-1849.

Park, R. (1989), "Evaluation of Ductility of Structures and Structural Assemblages from Laboratory Testing", Bulletin of The New Zealand National Society for Earthquake Engineering, Vol. 22, No. 3, September 1989, pp. 155-166.

Park, R. and Ruitong, D. (1988), "Ductility of Doubly Reinforced Concrete Beam Section”, ACI Structural Journal, Vol. 85, No. 2, March 1988, pp. 217-225.

Paulay, T. and Priestlay M.J.N. (1992), "Seismic Design in Reinforced Concrete and Masonry Buildings", John Wiley \& Sons Inc., New York, USA.

Pawirodikromo, W. (2012), "Seismologi Teknik \& Rekayasa Kegempaan", Penerbit Pustaka Pelajar, Yogyakarta, Indonesia.

Purwono, R.; Tavio; Imran, I.; dan Raka, I.G.P., (2007), “Tata Cara Perhitungan Struktur Beton untuk Bangunan Gedung (SNI 03-2847-2002) Dilengkapi Penjelasan (S-2002)", Penerbit ITS Press, Surabaya

Roeder, C.W., Lehman, D.E., and Bishop, E. (2010), "Strength and Stiffness of Circular Concrete-Filled Tubes", ASCE Journal of Structural Engineering, Vol. 12, Desember 2010, pp. 1545-1553. 